\title{
Bowel preparation for colorectal surgery: with and without mannitol
}

\author{
Shahnam Askarpour ${ }^{1}$, Mehran Peyvasteh², Ali-Asghar Dastyar ${ }^{3}$, Hazhir Javaherizadeh ${ }^{1}$ \\ ${ }^{1}$ Ahvaz Jundishapur University of Medical Sciences, Ahvaz, Iran \\ ${ }^{2}$ Department of Surgery, Ahvaz Jundishapur University of Medical Sciences, Ahvaz, Iran \\ ${ }^{3}$ Department of General Surgery, Imam Khomeini Hospital, Ahvaz Jundishapur University of Medical Sciences, Ahvaz, Iran
}

Prz Gastroenterol 2013; 8 (5): 305-307

DOI: $10.5114 /$ pg.2013.38733

Key words: bowel preparation, hypokalemia, hypernatremia, leukocytosis, mannitol.

Address for correspondence: Shahnam Askarpour Assoc. Prof., Ahvaz Jundishapur University of Medical Sciences, Imam Khomeini Hospital, Azadegan St, 6135873391 Ahvaz, Iran, phone: 98-611-2221102, e-mail: shahnam_askarpour@yahoo.com

\begin{abstract} mannitol has several side effects. ration with mannitol.

\section{Introduction}

Mannitol was recommended for bowel preparation in previously published literature [1]. Bowel preparation with mannitol has several side effects such as fluid and electrolyte disturbances, dehydration, nausea, vomiting, fever, and abdominal cramp [2]. Bowel preparation using mannitol may be associated with abdominal infection [3]. Today, polyethylene glycol as a standard method for bowel preparation is widely used in countries with high economic status. But in countries with low economic states, polyethylene is expensive and may not be available [4]. In our country due to some limitations, mannitol is widely used for bowel preparation.
\end{abstract}

Introduction: In our country due to some limitations, mannitol is widely used for bowel preparation. Bowel preparation with

Aim: To compare complication of mechanical bowel preparation with and without mannitol.

Material and methods: This case control study was carried out in Imam Khomeini and Abuzar children's hospitals. Sixty cases of patients who underwent colorectal surgery were included in this study. Pull-through, colostomy closure, and anorectoplasty were the surgical procedures. Subjects were randomly placed in the case or control group. Infection, electrolyte disturbances, fever, and leukocytosis were recorded. Multivariate analysis was done using PRISM. Odds ratio was calculate with $\mathrm{Cl}=95 \%$.

Results: Fourteen boys and 16 girls were included in group I. Ten boys and 20 girls were included in group II. Twenty colostomies, 6 pull-throughs, and 4 anorectoplasties were performed in group I. Twenty-one colostomies, 5 pull-throughs, and 4 anorectoplasties were done in group II. Mean age of the patients was $2.63 \pm 1.9$ and $2.66 \pm 1.68$ for group I and group II respectively $\left(p=0.262\right.$ ). Following bowel preparation with mannitol, 14 patients had mild fever with mean body temperature of $38.1^{\circ} \mathrm{C}$. Three subjects had postsurgical fever within $48 \mathrm{~h}$ of surgery. In group II, postoperative fever was found in 2 subjects.

Conclusions: Hypernatremia, hypokalemia, and leukocytosis were more common in patients who underwent bowel prepa-

\section{Aim}

The aim of this study was to compare bowel preparation with mannitol and without mannitol regarding wound infection and electrolyte disturbances.

\section{Material and methods}

This case control study was carried out in Imam Khomeini hospital. Sixty cases were included in this study. Indications for colorectal surgery were pullthrough, colostomy closure, and anorectoplasty. All subjects in case and control groups underwent enema for preparation. Oral antibiotics were prescribed for cases and controls in 3 doses preoperatively. A systemic antibiotic was prescribed for all subjects 30 min preoperatively. Subjects were randomly placed in the case or control group. Surgeons were blind to the type of preparation. Emergency cases, patients with proximal colostomy, and patients who received antibiotics for intra-abdominal infection were excluded from our study. Normal saline enema $(10 \mathrm{cc} / \mathrm{kg})$ was used for both groups. Mannitol 10\% (10 cc/kg) with Ringer serum was prescribed orally for the case group. Infection, electrolyte disturbances, fever, and leukocytosis were recorded. 
Table I. Comparison between two groups

\begin{tabular}{lccc} 
Parameter & Group I (mannitol) & Group II (without mannitol) & Value of $\boldsymbol{p}$ \\
\hline Mean age [year] & $2.63 \pm 1.9$ & $2.66 \pm 1.68$ & 0.262 \\
\hline $\mathrm{Na}$ & $141.13 \pm 4.41$ & $139.73 \pm 2.55$ & 0.002 \\
\hline $\mathrm{K}$ & $3.7 \pm 0.32$ & $4.39 \pm 0.45$ & 0.0006 \\
\hline WBC & $9146.6 \pm 2434.4$ & $7523.3 \pm 1098.8$ & $<0.001$ \\
\hline Defecation & $4.30 \pm 1.02$ & $3.10 \pm 0.99$ & 0.601 \\
\hline Bowel sound & $2.43 \pm 1.00$ & $2.03 \pm 0.92$ & 0.288 \\
\hline Wound infection & 1 & 2 &
\end{tabular}

Wound infection was determined when there was erythema that needed antibiotic treatment, and a wound with an indication for exploration for drainage. White blood cells $>10,000$ was considered as leukocytosis. Anastomotic leakage was determined using radiologic investigation or drainage of fecal material. Patients were examined daily until discharge and then 1 week after that. Multivariate analysis was done using PRISM. Odds ratio was calculated with $\mathrm{Cl}=95 \%$.

\section{Results}

Fourteen boys and 16 girls were included in group I. Ten boys and 20 girls were included in group II. Mean age of case and control groups had no significant difference $(p=0.262)$. Twenty colostomies, 6 pull-throughs, and 4 anorectoplasties were performed in group 1. Twenty-one colostomies, 5 pull-throughs, and 4 anorectoplasties were done in group II. Following bowel preparation with mannitol, 14 patients had mild fever (mean $38.1^{\circ} \mathrm{C}$ ). Three subjects had postsurgical fever within $48 \mathrm{~h}$ of surgery. In group II, postoperative fever was found in 2 subjects. The level of sodium was significantly higher in group I. The level of potassium was significantly lower in group I. White blood cells count was significantly higher in group I (Table I).

\section{Discussion}

Leukocyte count was significantly higher in patients with mannitol preparation. Sodium concentration was significantly higher among patients who underwent bowel preparation with mannitol. The level of potassium was significantly lower in patients who underwent bowel preparation with mannitol. Mannitol causes osmotic diuresis, dehydration, and has the risk of eliciting explosion with diathermy $[5,6]$.

In our study wound infection showed no significant difference between the two groups. This may be due to limitation in sample size. In another study, wound infection was significantly higher in patients who un- derwent bowel preparation with mannitol [7]. In the study by Zmora et al., there were no significant differences between the prep and non-prep group regarding complications except for diarrhea [8]. In the study by Scabini et al., who compared polyethylene glycol with a group without mechanical bowel preparation, the authors concluded that colon and rectal surgery may be safely performed without mechanical bowel preparation [9]. This finding supported our finding, because polyethylene glycol is safer than mannitol bowel preparation.

In the study by Balogh et al., the rate of septic complication was higher in colon preparation using the conventional method than preparation with mannitol [10]. In our study, the rate of infection was similar in both groups. However, sample size in our study was smaller than in the Balogh et al. study [10].

Most studies have shown that colorectal surgery without mechanical bowel preparation has fewer side effects, even with newer agents [7, 11]. In contrast, in a recent study on 190 patients who underwent colorectal surgery due to diverticulitis, there were no significant differences between groups in septic complication and mortality [12].

\section{Conclusions}

Rectal bowel preparation without mannitol is safe and is associated with less complications than bowel preparation with mannitol. In our setting, normal saline enema without mannitol may be an appropriate regimen and is recommended.

Limitation: Low sample size is the main limitation of our study.

\section{Acknowledgments}

The data used in this manuscript were from the thesis of Dr. Al-Asghar Dastyar. This study was supported by research affairs of Ahvaz Jundishapur University of Medical Sciences. 


\section{References}

1. Keighley M, Taylor E, Hares M, et al. Influence of oral mannitol bowel preparation on colonic microflora and the risk of explosion during endoscopic diathermy. Br J Surg 1981; 68: 554-6.

2. Fry RD, Mahmoud N, Maron DJ, et al. Colon and rectum. In: Sabiston textbook of surgery. Townsend CM, Beauchamp RD, Evers BM, Mattox KL (eds.) $18^{\text {th }}$ ed. Philadelphia, Pa: Saunders Elsevier 2008; 1404-5.

3. Bucher P, Gervaz P, Egger JF, et al. Morphologic alterations associated with mechanical bowel preparation before elective colorectal surgery: a randomized trial. Dis Colon Rec 2006; 49: 109-12.

4. Ameh E, Lukong C, Mshelbwala P, et al. One-day bowel preparation in children with colostomy using normal saline. Afr J Paediatr Surg 2011; 8: 291.

5. Ladas SD, Karamanolis G, Ben-Soussan E. Colonic gas explosion during therapeutic colonoscopy with electrocautery. World J Gastroenterol 2007; 13: 5295.

6. Davis GR, Santa Ana C, Morawski S, et al. Development of a lavage solution associated with minimal water and electrolyte absorption or secretion. Gastroenterology 1980; 78: 991.

7. Todorov AT, Mantchev ID, Atanasov TB. Traditional bowel preparation versus osmotic agent mannitol for preoperative colonic cleansing in elective colorectal surgery. Folia Med (Plovdiv) 2002; 44: 36-9.

8. Zmora O, Mahajna A, Bar-Zakai B, et al. Colon and rectal surgery without mechanical bowel preparation: a randomized prospective trial. Ann Surg 2003; 237: 363-7.

9. Scabini S, Rimini E, Romairone E, et al. Colon and rectal surgery for cancer without mechanical bowel preparation: one-center randomized prospective trial. World J Surg Oncology 2010; 8: 35.

10. Balogh A, Karadi J, Bence G, et al. Preparation of elective colon surgery using the manitol-ceftriaxone method. Orv Hetil 1992; 133: 343-7.

11. Bucher P, Gervaz P, Soravia C, et al. Randomized clinical trial of mechanical bowel preparation versus no preparation before elective left-sided colorectal surgery. Br J Surg 2005; 92: 409-14.

12. Van't Sant HP, Slieker JC, Hop WC, et al. The influence of mechanical bowel preparation in elective colorectal surgery for diverticulitis. Tech Coloproctol 2012; 16: 309-14.

Received: 10.11 .2012

Accepted: 16.02 .2013 